\title{
Transcriptional profiling reveals the expression of novel genes in response to various stimuli in the human dermatophyte Trichophyton rubrum
}

\author{
Nalu TA Peres ${ }^{1}$, Pablo R Sanches ${ }^{1}$, Juliana P Falcão ${ }^{1,3}$, Henrique CS Silveira', Fernanda G Paião ${ }^{1}$, \\ Fernanda CA Maranhão', Diana E Gras', Fernando Segato', Rodrigo A Cazzaniga', Mendelson Mazucato', \\ Jeny R Cursino-Santos', Roseli Aquino-Ferreira', Antonio Rossi², Nilce M Martinez-Rossi ${ }^{1{ }^{*}}$
}

\begin{abstract}
Background: Cutaneous mycoses are common human infections among healthy and immunocompromised hosts, and the anthropophilic fungus Trichophyton rubrum is the most prevalent microorganism isolated from such clinical cases worldwide. The aim of this study was to determine the transcriptional profile of T. rubrum exposed to various stimuli in order to obtain insights into the responses of this pathogen to different environmental challenges. Therefore, we generated an expressed sequence tag (EST) collection by constructing one cDNA library and nine suppression subtractive hybridization libraries.

Results: The 1388 unigenes identified in this study were functionally classified based on the Munich Information Center for Protein Sequences (MIPS) categories. The identified proteins were involved in transcriptional regulation, cellular defense and stress, protein degradation, signaling, transport, and secretion, among other functions. Analysis of these unigenes revealed 575 T. rubrum sequences that had not been previously deposited in public databases.

Conclusion: In this study, we identified novel T. rubrum genes that will be useful for ORF prediction in genome sequencing and facilitating functional genome analysis. Annotation of these expressed genes revealed metabolic adaptations of T. rubrum to carbon sources, ambient $\mathrm{pH}$ shifts, and various antifungal drugs used in medical practice. Furthermore, challenging T. rubrum with cytotoxic drugs and ambient pH shifts extended our understanding of the molecular events possibly involved in the infectious process and resistance to antifungal drugs.
\end{abstract}

\section{Background}

Trichophyton rubrum is a cosmopolitan dermatophyte that colonizes human skin and nails and is the most prevalent cause of human dermatophytoses [1,2]. During the initial stages of the infection, dermatophytes induce the expression of adhesins and unspecific proteases and keratinases that have optimum activity at acidic $\mathrm{pH}$ values [3], which is probably because the human skin has an acidic $\mathrm{pH}$ value [4]. The secretion of these proteases, which have been identified as an important step in fungal pathogenicity and virulence [5,6], act on keratinous and nonkeratinous substrates to release peptides

\footnotetext{
* Correspondence: nmmrossi@usp.br

${ }^{1}$ Departamento de Genética, Faculdade de Medicina de Ribeirão Preto,
} Universidade de São Paulo, Ribeirão Preto 14049-900, SP, Brazil that are further hydrolyzed to amino acids by putative peptidases. The metabolism of some amino acids shifts the extracellular $\mathrm{pH}$ from acidic to alkaline values at which most known keratinolytic proteases have optimal enzymatic activity [7-9]. T. rubrum also responds to the environmental $\mathrm{pH}$ by altering its gene expression profile $[9,10]$.

Molecular studies have been performed with human pathogens such as Candida albicans, Histoplasma capsulatum, and Paracoccidioides brasiliensis, and the results thus obtained have helped to determine the fungal transcriptional profile and characterize the genes involved in host-pathogen interactions and environmental stress responses [11-13]. Previously, a collection of $T$. rubrum expressed sequence tags (ESTs) was obtained from distinct developmental phases $[14,15]$. However,
C Biomed Central

C 2010 Peres et al; licensee BioMed Central Ltd. This is an Open Access article distributed under the terms of the Creative Commons Attribution License (http://creativecommons.org/licenses/by/2.0), which permits unrestricted use, distribution, and reproduction in any medium, provided the original work is properly cited. 
determining the transcriptional profiles in response to different cell stimuli is necessary for extending our understanding of diverse cellular events, and the results from such studies may reveal new signal transduction networks and the activation of specific metabolic pathways. Functional analysis of the genes involved in these molecular events will help in evaluating their roles as putative cellular targets in the development of new antifungal agents.

Our study aimed to extend the T. rubrum genomic database by adding expressed gene resources that cover different aspects of cellular metabolism. Moreover, the data can help to generate useful information to screen valuable genes for functional and postgenomic analyses. The EST collection described here revealed the metabolic adaptations of the human pathogen T. rubrum to changes in the ambient $\mathrm{pH}$ and carbon sources and also provided information on the adaptive responses to several cytotoxic drugs.

\section{Results and Discussion}

The EST collection described here was obtained from a cDNA library and nine independent suppression subtractive hybridization (SSH) libraries. A total of 2735 high-quality sequences with an average sequence length of 339 nucleotides were generated. These ESTs were assembled in 296 contigs and 1092 singletons, resulting in 1388 unique sequences with a redundancy of $49.3 \%$ (Table 1). The majority of the contigs assembled ESTs from a maximum of four libraries, suggesting that these genes are expressed under environmental stress or specific growth conditions. The search results and GenBank submission numbers for each EST are shown in Additional file 1. Analysis of these 1388 unigenes revealed 666 sequences that had no similarity to the sequences in the GenBank dbEST, which contains 37890 T. rubrum sequences. Of the 666 sequences, 404 had no similarities to the sequences in the nonredundant database (Table 1). Additional analysis revealed that of the 666 sequences, 91 were present in the $\operatorname{Tr}$ ED database [16]. Thus, 575 novel genes were identified, representing a marked increase in the number of expressed genes identified in the dermatophyte $T$. rubrum. These genes and the corresponding libraries in which they were identified are highlighted in Additional file 2.

The 1388 unigenes identified in this study were functionally classified based on the Munich Information Center for Protein Sequences (MIPS) categories. The classification led to the identification of putative proteins involved in transcriptional regulation, cellular defense and stress, protein degradation, signaling, transport, and secretion, among other functions (Additional file 2). However, many of these unigenes $(54.28 \%$ involved in the developmental phases, $46.87 \%$ in exposure to cytotoxic drugs, $33.93 \%$ in $\mathrm{pH}$ sensing, and $30.81 \%$ in carbon source responses) were not classified by the MIPS annotation (Fig. 1). Growth of T. rubrum in a keratinocyte serum-free medium (Library 1) revealed 207 novel genes (Table 1; Additional file 2) in comparison to the T. rubrum sequences deposited in public databases, which include an EST collection that was previously generated during the growth of $T$. rubrum in Sabouraud liquid medium [14]. This suggests that the expression of these 207 novel genes is nutrientdependent. Functional grouping of these genes, which were identified on the basis of their ESTs, revealed their possible involvement in various cellular processes such as basic metabolism, conidial germination, and hyphal growth, among other functions (see Additional file 2).

\section{Challenging $T$. rubrum with cytotoxic drugs}

Numerous signal-transduction pathways are used by fungi to sense and overcome the toxic effects of antifungal drugs [17]. Our aim in this study was to identify metabolic events that occur during the initial stages of drug exposure; therefore, we created an EST collection by challenging the dermatophyte $T$. rubrum with cytotoxic drugs, including most of the antifungals used in medical practice. These drugs, which belong to the azole and allylamine/thiocarbamate classes, were fluconazole (FLC), imazalil (IMZ), itraconazole (ITRA), ketoconazole (KTC), tioconazole (TIO), and terbinafine (TRB). All of these compounds inhibit the biosynthesis of ergosterol. T. rubrum was also challenged with the following cytotoxic drugs: amphotericin $B(A M B)$, griseofulvin (GRS), benomyl (BEN), undecanoic acid (UDA), cycloheximide (CHX), chloramphenicol (CAP), acriflavin (ACR), ethidium bromide (EB), and 4-nitroquinoline 1-oxide (4NQO) [18-20]. Approximately 300 unigenes were identified in these experiments and only 70 of these were exclusive to drug challenge (Additional file 2). Drug exposure induced the transcription of several multidrug resistance genes, as previously reported in studies in which T. rubrum was exposed to sub-inhibitory levels of KTC, AMB, or other drugs [21,22]. One of these genes [GenBank: FE526598] encodes a putative multidrug resistance protein (MDR) that accumulates in the mycelia when the organism is independently exposed to various cytotoxic agents. Overexpression of this gene has been previously reported in the myceliaof T. rubrum exposed to the antimycotic agents ACR, GRS, ITRA, or FLC [23]. Disruption of this gene increased the susceptibility of the mutant strain to TRB in comparison with the control, suggesting that this transporter modulates $T$. rubrum drug susceptibility [23].

Some of the ESTs that were overexpressed in the mycelia of T. rubrum upon exposure to cytotoxic drugs 
Table 1 General features of $T$. rubrum EST libraries

\begin{tabular}{|c|c|c|c|c|c|c|c|c|}
\hline \multirow[t]{2}{*}{ Library } & \multirow[t]{2}{*}{$\begin{array}{c}\text { GenBank accession } \\
\text { No. }\end{array}$} & \multirow{2}{*}{$\begin{array}{l}\text { No. of } \\
\text { raw } \\
\text { ESTs }\end{array}$} & \multirow[t]{2}{*}{$\begin{array}{l}\text { No. of } \\
\text { contigs }\end{array}$} & \multirow[t]{2}{*}{$\begin{array}{l}\text { No. of } \\
\text { singletons }\end{array}$} & \multirow[t]{2}{*}{$\begin{array}{l}\text { Unique } \\
\text { genes }\end{array}$} & \multirow{2}{*}{$\begin{array}{l}\text { No. of unigenes } \\
\text { matching GenBank } \\
\text { database (NR) }^{(a)}\end{array}$} & \multicolumn{2}{|c|}{$\begin{array}{l}\text { No. of unigenes without match to } \\
\text { GenBank dbEST database }\end{array}$} \\
\hline & & & & & & & $\begin{array}{c}\text { matching } \\
\text { GenBank } \\
\text { database (NR) }^{(\mathrm{c})} \\
\end{array}$ & $\begin{array}{c}\text { without match to } \\
\text { GenBank database } \\
\text { (NR) }\end{array}$ \\
\hline Total & FE524602-FE527336 & 2735 & 296 & 1092 & 1388 & $681(49.1 \%)$ & $262(18.9 \%)$ & $404(29.1 \%)$ \\
\hline 1 & FE524602-FE525578 & 977 & 75 & 545 & 620 & 235 (37.9\%) & $73(11.8 \%)$ & $207(33.4 \%)$ \\
\hline 2 & FE525579-FE525681 & 103 & 23 & 14 & 37 & $24(64.9 \%)$ & $18(48.6 \%)$ & $10(27.0 \%)$ \\
\hline 3 & FE525682-FE525782 & 101 & 7 & 76 & 83 & $46(55.4 \%)$ & 19 (22.9\%) & $20(24.1 \%)$ \\
\hline 4 & FE525783-FE526029 & 247 & 64 & 56 & 120 & $62(51.7 \%)$ & 31 (25.8\%) & $36(30.0 \%)$ \\
\hline 5 & FE526030-FE526148 & 119 & 7 & 50 & 57 & $26(45.6 \%)$ & $7(12.3 \%)$ & 17 (29.8\%) \\
\hline 6 & FE526149-FE526246 & 98 & 12 & 5 & 17 & $11(64.7 \%)$ & $5(29.4 \%)$ & $3(17.6 \%)$ \\
\hline 7 & FE526247-FE526554 & 308 & 36 & 59 & 95 & $69(72.6 \%)$ & $25(26.3 \%)$ & 17 (17.9\%) \\
\hline 8 & FE526555-FE526754 & 200 & 30 & 18 & 48 & $27(56.3 \%)$ & $21(43.8 \%)$ & $15(31.3 \%)$ \\
\hline 9 & $\begin{array}{c}\text { FE526755-FE527126 } \\
\text { and FG235008- } \\
\text { FG235038 }\end{array}$ & 372 & 43 & 248 & 291 & $162(55.7 \%)$ & $53(18.2 \%)$ & $74(25.4 \%)$ \\
\hline 10 & FE527127-FE527336 & 210 & 26 & 143 & 169 & $106(62.7 \%)$ & $34(20.1 \%)$ & $23(13.6 \%)$ \\
\hline
\end{tabular}

(a) Unigenes with similarity to the sequences in the nonredundant NCBI database (1e-3) using BLASTx.

(b) Unigenes with no similarity to the sequences in the dbEST-NCBI database (1e-20) using BLASTn-Organism: Trichophyton rubrum (taxid:5551),

(c) $T$. rubrum protein sequences identified in this database were excluded from this analysis.

showed similarities to genes encoding the Pol protein [GenBank: FE526593], carboxylic ester hydrolase [GenBank: FE525618], DNA mismatch repair protein [GenBank: FE525624], and cooper resistance-associated Ptype ATPase protein [GenBank: FE526224], among others. These results had been previously validated by northern blot analyses in mycelia of T. rubrum grown in the presence of TRB or GRS [20]. Upregulation of ESTs similar to the pol gene of the Cgret retrotransposon element from Glomerella cingulata (anamorph: Colletotrichum gloeosporioides) suggests that T. rubrum evinces an adaptive response to environmental stress.
Interestingly, overexpression of this gene was also observed in mycelia of $T$. rubrum grown in keratin as the carbon source (Additional file 2), which suggests the involvement of this retrotransposon in nonspecific responses, leading to stress adaptation.

Overexpression of an EST encoding salicylate 1-monooxigenase, a naphthalene-degrading enzyme [GenBank: FE525605] (Additional file 2), was exclusive to $T$. rubrum that had been challenged with cytotoxic drugs, including TRB (Library 2). A possible mechanism of resistance to TRB was evidenced in the model fungus Aspergillus nidulans and involved the overexpression of

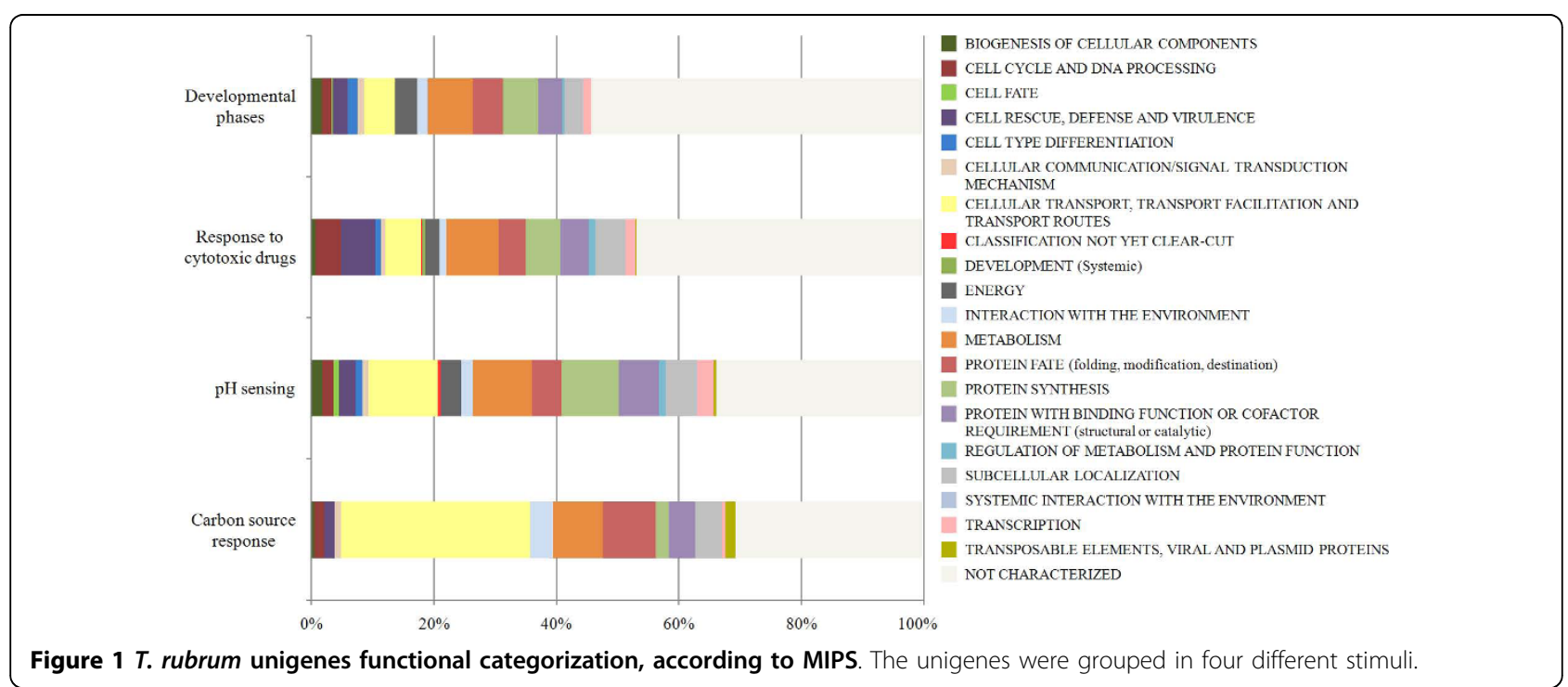


the salicylate 1-monooxigenase gene salA, probably due to a multicopy effect [24]. Moreover, plasmids carrying the salA gene of $A$. nidulans were able to transform a T. rubrum strain from TRB-sensitive to TRB-resistant, suggesting that a similar resistance mechanism could help T. rubrum to overcome the inhibitory effect of TRB, which has a naphthalene nucleus present in its molecular structure (not shown).

\section{$\mathrm{pH}$ and carbon source signaling}

Among the most important virulence factors identified in dermatophytes are proteases that have optimal activity at acidic $\mathrm{pH}$ and are secreted during the initial stages of fungal infection $[3,25,26]$. The hydrolysis of skin proteins releases amino acids such as glycine, the metabolism of which shifts the extracellular $\mathrm{pH}$ from acidic to alkaline values [8]. This effect is required for the growth and maintenance of the dermatophyte in the host [7-9,27]. Therefore, identification of T. rubrum genes that are differentially expressed in response to shifts in the ambient $\mathrm{pH}$ provides useful information on $\mathrm{pH}$ sensing during host infection. When the media was supplemented with glucose as the carbon source, we identified 339 genes that were overexpressed at $\mathrm{pH} 5.0$ and 169 genes that were overexpressed in response to alkaline $\mathrm{pH}$ conditions (Additional file 2). Functional grouping of these ESTs led to the identification of genes involved in various cellular processes, such as membrane remodeling, cellular transport, iron uptake, defense, metabolism, signal transduction, and virulence.

Interestingly, the transcription of the gene encoding an acetamidase [GenBank: FE526983] was stimulated in an acidic milieu (Additional file 2). This enzyme hydrolyses acetamide, releasing acetate and ammonia. Acetate is metabolized to acetyl-CoA by acetyl-CoA synthase, with the concomitant secretion of ammonia, which raises the extracellular $\mathrm{pH}$ to alkaline values [28-30]. The metabolism of amino acids that generate cytoplasmic acetyl-CoA shifts the extracellular $\mathrm{pH}$ from acidic to alkaline values [31], an effectobserved in in vitro cultures of T. rubrum [8]. The metalloenzyme urease (the T. rubrum urease gene [GenBank: FE526454] was identified in our unigenesdatabase) catalyzes the hydrolysis of urea to ammonia during the parasitic cycle of Coccidioides posadasii and also creates an alkaline microenvironment at the infection site. Ammonia secretion contributes to host tissue damage, thereby enhancing the virulence of this human respiratory pathogen [32] (Table 2).

Overexpression of some genes under acidic $\mathrm{pH}$ conditions was confirmed by northern blot analysis (Fig. 2A). One of these encodes a protein carrying the FYVE zinc finger domain [GenBank: FE526741]. FYVE domains are found in several eukaryotic nonnuclear proteins that are involved in many cellular functions, including cytoskeletal regulation, signal transduction, and vesicle transport $[33,34]$. Most of the proteins that carry the FYVE domain function in the recruitment of cytosolic proteins by binding to phosphatidylinositol 3-phosphate, which is mainly found in the endosome and functions as a regulator of endocytic membrane trafficking [35]. Interestingly, the anchoring of FYVE proteins to phosphatidylinositol 3-phosphate-enriched membranes is strongly $\mathrm{pH}$-dependent and is enhanced by an acidic cytosolic environment $[36,37]$. A relevant gene that is overexpressed at alkaline $\mathrm{pH}$ values encodes an iron-sulfur cluster protein [GenBank: FE527227], a cofactor for several proteins involved in electron transfer in redox and nonredox catalysis, in gene regulation, and as sensors of oxygen and iron [38]. Some genes involved in the acquisition of iron by $C$. albicans are also overexpressed at $\mathrm{pH}$ 8.0, suggesting that alkaline $\mathrm{pH}$ induces iron starvation [39]. Thus, genes overexpressed at either acidic or alkaline $\mathrm{pH}$ values are probably involved in the initial stages of dermatophyte infection and maintenance in the host tissue, respectively.

Identification of the ESTs involved in keratin metabolism may also help in determining the genes necessary for installation and maintenance of the pathogen in the host. We identified 95 keratin-enriched transcripts, and 17 ESTs which were involved in glucose metabolism (Table 1; Additional file 2). It was previously observed that the $\mathrm{pH}$ of the medium remained at a value of approximately 5.0 during mycelial growth when glucose was the carbon source. In contrast, during growth on keratin or a mixture of glycine and glycerol, the extracellular $\mathrm{pH}$ shifted from acidic to alkaline, reaching $\mathrm{pH}$ values from 8.3 to $8.9[8,9]$. Growth on keratin at alkaline $\mathrm{pH}$ values revealed the overexpression of several proteases and membrane transporter protein genes (Additional file 2) such as subtilisin protease SUB 5 [GenBank: FE526467], metalloprotease Mep3 [GenBank: FE526356], MFS oligopeptide transporter [GenBank: FE526458], MDR protein [GenBank: FE526598], $\mathrm{Cu}^{2}$ ${ }^{+}$-ATPase [GenBank: FE526224], V-type ATPase, subunit B [GenBank: FE526350], and an aminoacid permease [GenBank: FE526515] [9,40]. Most of these genes were not overexpressed when the initial culture $\mathrm{pH}$ was adjusted to 8.0 and glucose was used as the carbon source (Library 10) (Additional file 2). This suggests that a combination of an ambient $\mathrm{pH}$ shift and keratin as the carbon source is necessary to induce the expression of these genes. Interestingly, the gene encoding NIMA interactive protein [GenBank: FE526568] was overexpressed in keratin cultures, in response to cytotoxic drugs, and after mycelial exposure for $30 \mathrm{~min}$ at $\mathrm{pH}$ 5.0, suggesting that this gene may be involved in unspecific stress responses. Overexpression of the 
Table 2 Putative proteins required for fungal virulence.

\begin{tabular}{|c|c|c|c|c|}
\hline $\begin{array}{l}\text { Accession no. } \\
\text { of one EST }\end{array}$ & Library & Virulence determinant & Function in fungi & $\begin{array}{l}\text { Reference } \\
\text { number }\end{array}$ \\
\hline FE526884 & 9 & isocitrate lyase & Glyoxylate cycle enzyme & {$[43,44]$} \\
\hline FE525405 & 1 & malate synthase & Glyoxylate cycle enzyme & {$[43,44]$} \\
\hline FE525119 & 1 & citrate synthase & Glyoxylate cycle enzyme & {$[43,44]$} \\
\hline FE526004 & 4 & phospholipase B & $\begin{array}{l}\text { Gene inactivation attenuates virulence in Cryptococcus neoformans and } \\
\text { Candida albicans }\end{array}$ & {$[63,64]$} \\
\hline FE526464 & 7 & subtilisin-like protease Sub3 & $\begin{array}{l}\text { Sub3 is a dominant protease secreted by Trichophyton rubrum during } \\
\text { host infection }\end{array}$ & [65] \\
\hline FE526467 & $1,7,10$ & subtilisin-like protease Sub5 & Putative Trichophyton rubrum virulence factor & [9] \\
\hline FE526356 & 7 & metalloprotease Mep3 & MEP3 is produced by $M$. canis during guinea pigs infection & [66] \\
\hline FE526553 & 7 & metalloprotease Mep4 & $\begin{array}{l}\text { Mep4 is a dominant protease secreted by Trichophyton rubrum during } \\
\text { host infection }\end{array}$ & [65] \\
\hline FE526905 & 9 & carboxypeptidase & $\begin{array}{l}\text { Important for the assimilation of nitrogenous substrates during infection } \\
\text { and contributes to the virulence of dermatophytes }\end{array}$ & [50] \\
\hline FE524895 & 1 & dipeptidyl-peptidase V & $\begin{array}{l}\text { Dipeptidyl peptidases as potential virulence factors for Microsporum } \\
\text { canis }\end{array}$ & {$[67]$} \\
\hline FE526224 & $2,7,8$ & $\begin{array}{l}\text { copper resistance-associated P- } \\
\text { type ATPase }\end{array}$ & $\begin{array}{l}\text { Cu-ATPase mutants showed reduced virulence in Listeria monocytogenes } \\
\text { and Criptococcus neoformans }\end{array}$ & {$[52,53,68]$} \\
\hline FE526598 & $2,7,8$ & TruMDR2 & $\begin{array}{l}\text { Gene inactivation attenuates the virulence of Trichophyton rubrum in } \\
\text { vitro }\end{array}$ & [40] \\
\hline FE525063 & 1 & mannosyltransferase & $\begin{array}{l}\text { Gene inactivation attenuates the virulence of Candida albicans and } \\
\text { Aspergillus fumigatus }\end{array}$ & {$[69,70]$} \\
\hline FE526454 & 7 & urease & $\begin{array}{l}\text { Gene inactivation reduces the amount of ammonia secreted in vitro } \\
\text { and attenuates the virulence of Coccidioides posadasii }\end{array}$ & [32] \\
\hline FE526352 & 1,7 & $\begin{array}{l}\text { glucosamine-6-phosphate } \\
\text { deaminase }\end{array}$ & $\begin{array}{l}\text { Gene inactivation attenuates the virulence of Candida albicans in a } \\
\text { murine model }\end{array}$ & [71] \\
\hline FE524999 & 1 & $\begin{array}{l}\text { glyceraldehyde-3-phosphate } \\
\text { dehydrogenase (GAPDH) }\end{array}$ & $\begin{array}{l}\text { GAPDH contributes to the adhesion of Paracoccidioides brasiliensis to } \\
\text { host tissues and to the dissemination of infection. }\end{array}$ & [72] \\
\hline FE527290 & 10 & thioredoxin TrxA & Putative Trichophyton mentagrophytes virulence factor & [73] \\
\hline
\end{tabular}

The overexpression of the ESTs from SSH libraries was confirmed by reverse Northern hybridization and/or Northern blot.

NIMA interactive protein gene in mycelia of T. rubrum exposed to acid $\mathrm{pH}$ (Fig. 2A) or grown in keratin as the only carbon source (Fig. 2B) was confirmed by northern blot analysis. In fact, this protein is a member of the NIMA family of kinases and is expressed in response to unspecific cellular stresses [41]. Furthermore, the hsp30 gene [GenBank: FE526362] and a transcript with no significant similarity [GenBank: FE526434] were confirmed to be overexpressed when keratin was used as the carbon source (Fig. 2B). The HSP3O gene of Saccharomyces cerevisiae is strongly induced when the fungus is exposed to various stresses, including heat shock and glucose starvation [42]. Similar to many other heat shock proteins, HSP30 increases cellular tolerance to stress.

\section{Genes that contribute to virulence}

The ESTs shown in Table 2 reveal T. rubrum genes that encode putative proteins similar to the virulence factors identified in other fungi. Three of the five glyoxylate cycle enzymes were identified in our EST database, i.e., isocitrate lyase and malate synthase, which are key enzymes of this cycle, together with citrate synthase.
The glyoxylate cycle is required for the full virulence of C. albicans [43], Mycobacterium tuberculosis [44,45], and P. brasiliensis [46]. Moreover, nutritional stress conditions in vitro also require upregulation of the glyoxylate cycle enzymes in P. brasiliensis [46].

Secreted enzymes such as phospholipases, peptidases, and proteases are crucial for dermatophyte virulence since these pathogens infect the stratum corneum, nails, or hair [47-49]. During infection, T. rubrum carboxypeptidases may contribute to fungal virulence by cooperating with endoproteases and aminopeptidases to degrade compact keratinized tissues into short peptides and amino acids that can be assimilated [50] (Table 2).

Various membrane transporters are virulence factors that are commonly involved in bacterial and fungal pathogenesis and ensure successful colonization of the host. For example, transmembrane proteins involved in the transport of metallic ions appear to play an important role in microbial pathogenesis [51] as demonstrated in the $\mathrm{Cu}^{2+}$-ATPase mutants of Listeria monocytogenes [52] and Criptococcus neoformans [53] that show reduced virulence. In the latter case, the $\Delta v p h 1$ mutant did not display laccase activity, which is an essential 
(A)

\section{NIMA interactive protein}
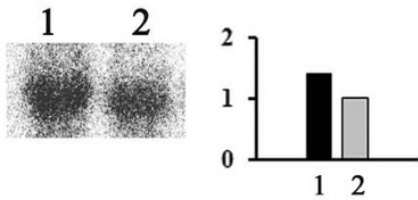

aminoacid permease
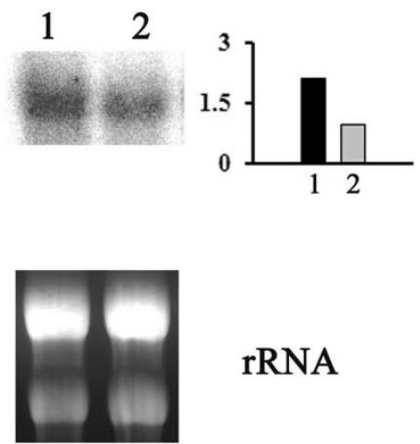

FYVE zinc finger domain

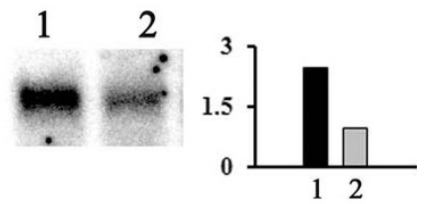

18S ribosomal RNA

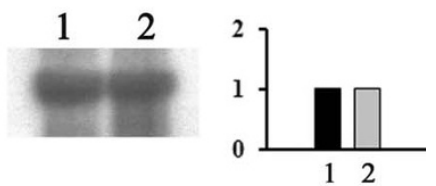

(B)
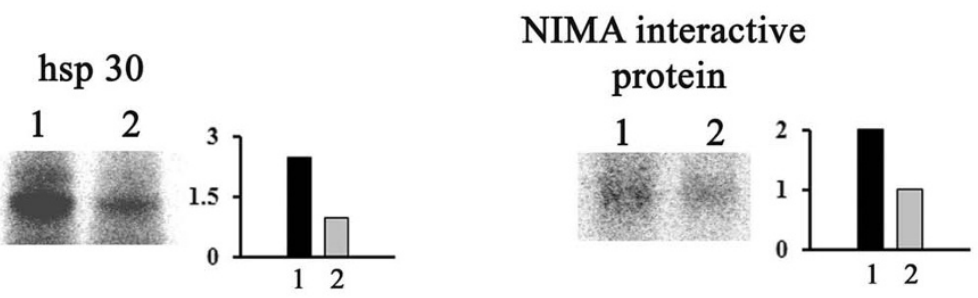

no match

\section{S ribosomal RNA}
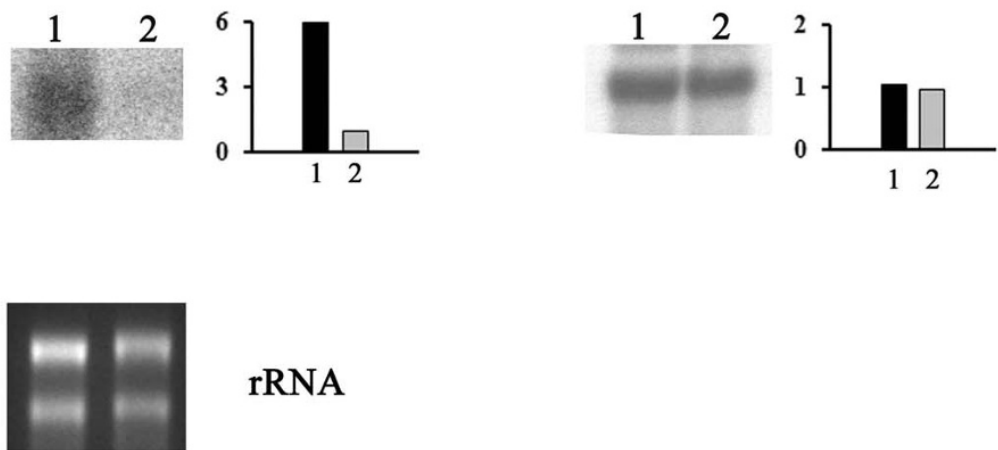

rRNA

Figure 2 Northern blot analysis of transcripts using total RNA. (A) Overexpression of genes encoding the NIMA interactive protein [GenBank: FE526568], FYVE protein [GenBank: FE526741], and aminoacid permease [GenBank: FE526515] in T. rubrum mycelia exposed to acidic pH for 30 min (Library 8). Lanes 1 and 2 represent the $\mathrm{H} 6$ strain incubated at pH 5.0 and pH 8.0 (control), respectively. (B)Overexpression of genes encoding hs p30 [GenBank: FE526362], NIMA interactive protein [GenBank: FE526568], and a no-match transcript [GenBank: FE526434] in T. rubrum grown in keratin for $72 \mathrm{~h}$ (Library 7). Lanes 1 and 2 represent the $\mathrm{H} 6$ strain cultured with keratin or glucose (control) as the carbon source, respectively. Ethidium-bromide-stained rRNA bands are shown to allow comparison of the quantities of loaded RNAs. Hybridization with the $18 \mathrm{~S}$ rRNA gene was performed as an additional loading control for northern blots. Bars show fold expression, determined from the intensity measured by densitometric analysis. 
virulence factor of this pathogen [53]. Moreover, an ATP-binding cassette $(\mathrm{ABC})$ transporter listed in Table 2 is overexpressed in mycelia cultured in keratin, suggesting its involvement in T. rubrum pathogenicity. In addition, the strain carrying a disrupted version of this MDR gene ( $\triangle$ TruMDR2) showed low infectious capability characterized by reduced growth of $T$. rubrum on human nails [40].

\section{Conclusions}

We identified 575 novel ESTs and obtained new molecular data related to T. rubrum growth, $\mathrm{pH}$ and carbon source signaling, and stress responses to antifungal challenges. It is clear that additional studies are necessary to define the functioning of whole genes and fully understand the regulation of these complex adaptive responses. However, the various ESTs identified in this work provide new insights into different aspects of $T$. rubrum biology, revealing new sources for functional genome analysis. T. rubrum genes that encode putative proteins similar to virulence factors described for other fungi were among the ESTs identified. The transcriptional profile also suggested that several genes could function in environmental stress responses. Thus, our study can help to better understand the molecular mechanisms of the adaptive responses possibly involved in dermatophyte infection and antifungal resistance.

\section{Methods}

\section{Strains and culture conditions}

The H6 (ATCC MYA-3108) and F6 mutant (a fluconazole-resistant strain isolated in our laboratory) strains of T. rubrum were cultured on Sabouraud dextrose agar plates (SDA) as described earlier [54]. The F6 cultures were supplemented with fluconazole $(200 \mu \mathrm{g} / \mathrm{mL})$. Conidia from these strains were used to construct the cDNA (library 1) or were inoculated in Sabouraud dextrose broth (SDB) and incubated for $72 \mathrm{~h}$ at $28^{\circ} \mathrm{C}$ on an orbital shaker at $180 \mathrm{rpm}$. The resulting mycelia were aseptically transferred to the desired culture media, and these were used to construct each of the SSH libraries.

\section{Construction of the libraries}

One cDNA library (Library 1) and nine SSH libraries (Libraries 2 to 10) were constructed. The SSH libraries were performed between the tester and driver DNA, with the cDNA population containing the differentially expressed transcripts being the tester, and the reference cDNA (control) being the driver.

Total RNA was extracted from approximately $100 \mathrm{mg}$ of frozen mycelia obtained from each procedure by using the Nucleospin ${ }^{\bullet}$ RNA Plant (Macherey-Nagel) or TRIZOL Reagent (Invitrogen), and treated with DNase Amp Grade (Invitrogen), in accordance with the manufacturer's instructions. Double-stranded cDNAs were obtained with the SMART PCR Synthesis kit (BD Biosciences) to amplify the cDNAs before the SSH procedure or the cDNA cloning step. The exceptions were libraries 2, 6, and 7, in which poly $\left(\mathrm{A}^{+}\right) \mathrm{RNA}$ was isolated from total RNA using Oligotex mRNA spin columns (Qiagen) or the PolyA Tract ${ }^{\circ}$ mRNA Isolation System (Promega). Library 1 (cDNA library) was constructed with the Creator SMART cDNA Library Construction Kit (BD Biosciences). SfiI-digested cDNAs were unidirectionally cloned into the pDNR-LIB vector and transformed into Escherichia coli TOP10F' electrocompetent cells. Libraries 2 to 10 were prepared by using the PCRSelect cDNA Subtraction kit (BD Biosciences). The cDNAs obtained from each SSH were cloned into the pCR 2.1 TOPO TA cloning system (Invitrogen) or pGEM-T cloning vector (Promega) and transformed into Escherichia coli Mos-Blue-competent cells.

\section{Library 1. Developmental phase-enriched transcripts}

Conidia from the H6 strain were incubated in keratinocyte serum-free medium (KGM-SFM, Gibco) for 16, 24, 48 , and $72 \mathrm{~h}$ at $37^{\circ} \mathrm{C}$. The cDNA transcribed from total RNA extracted from mycelia incubated in each experiment were mixed and used to construct the cDNA library as described above.

\section{Library 2. Cytotoxic drug-enriched transcripts}

Mycelia obtained from the H6 strain were exposed to each of the following cytotoxic drugs: ACR $(2.5 \mu \mathrm{g} / \mathrm{mL})$, BEN $(2.5 \mu \mathrm{g} / \mathrm{mL})$, CAP $(50 \mathrm{mg} / \mathrm{mL})$, CHX $(30 \mathrm{mg} / \mathrm{mL})$, EB $(2.5 \mu \mathrm{g} / \mathrm{mL})$, FLC $(130 \mu \mathrm{g} / \mathrm{mL})$, 4NQO $(10 \mu \mathrm{g} / \mathrm{mL})$, GRS $(2.0 \mu \mathrm{g} / \mathrm{mL})$, IMZ $(4.0 \mu \mathrm{g} / \mathrm{mL})$, ITRA $(30 \mu \mathrm{g} / \mathrm{mL})$, KTC $(10 \mu \mathrm{g} / \mathrm{mL})$, TRB $(0.1 \mu \mathrm{g} / \mathrm{mL})$, TIO $(0.5 \mu \mathrm{g} / \mathrm{mL})$, or UDA $(50 \mu \mathrm{g} / \mathrm{mL})$. The final concentration of each drug corresponds to its sub-inhibitory concentration. The cultures were incubated for $15 \mathrm{~min}$ at $28^{\circ} \mathrm{C}$, aiming the identification of genes expressed early during exposure to cytotoxic drugs. SSH was performed between the tester (mixture of cDNA transcribed from total RNA extracted from mycelia exposed to each drug) and driver (mRNA obtained from mycelia incubated into drug-free medium).

\section{Library 3. AMB-enriched transcripts}

Tester: mycelia obtained from the H6 strain were aseptically transferred to RPMI 1640 (Gibco) containing AMB $(0.5 \mu \mathrm{g} / \mathrm{mL})$ and incubated for $90 \mathrm{~min}$ at $28^{\circ} \mathrm{C}$. Driver: mycelia were transferred to a drug-free medium.

Library 4. FLC-enriched transcripts in the F6 mutant

Tester: mycelia from the F6 strain were transferred to fresh SDB containing FLC $(250 \mu \mathrm{g} / \mathrm{mL})$, and incubated for $1 \mathrm{~h}$ at $28^{\circ} \mathrm{C}$. Driver: mycelia from the $\mathrm{H} 6$ strain were inoculated in the drug-free medium.

\section{Library 5. FLC-repressed transcripts in the F6 mutant}

Tester: mycelia from the H6 strain were aseptically transferred to fresh SDB, and incubated for $1 \mathrm{~h}$ at $28^{\circ} \mathrm{C}$. 
Driver: mycelia from the F6 strain were aseptically transferred to SDB containing FLC $(250 \mu \mathrm{g} / \mathrm{mL})$.

\section{Library 6. Glucose-enriched transcripts}

Tester: mycelia from the H6 strain were transferred to minimal medium supplemented with $55 \mathrm{mM}$ glucose and $70 \mathrm{mM}$ sodium nitrate (MM) [55] at $\mathrm{pH} 5.0$ and incubated for $72 \mathrm{~h}$ at $28^{\circ} \mathrm{C}$. Driver: mycelia were aseptically transferred to keratin medium (KM) containing MM supplemented with $2.5 \mathrm{~g} / \mathrm{L}$ keratin (Sigma) as the carbon source ( $\mathrm{pH}$ 5.0).

\section{Library 7. Keratin-enriched transcripts}

Tester: mycelia from the H6 strain were transferred to $\mathrm{KM}$ and incubated for $72 \mathrm{~h}$ at $28^{\circ} \mathrm{C}$. Driver: mycelia were transferred to MM [55].

\section{Library 8. pH 5.0-enriched transcripts (30-min exposure)}

Tester: mycelia from the H6 strain were transferred to MM [55] containing $2.0 \mathrm{mM}$ inorganic phosphate (Pi) (low-Pi MM) (pH 5.0), and incubated for $30 \mathrm{~min}$ at $28^{\circ}$ C. Driver: mycelia were transferred to low-Pi MM (pH 8.0).

\section{Library 9. $\mathrm{pH}$ 5.0-enriched transcripts (60-min exposure)}

Tester: mycelia from the $\mathrm{H} 6$ strain were transferred to low-Pi MM (pH 5.0), and incubated for $1 \mathrm{~h}$ at $28^{\circ} \mathrm{C}$. Driver: mycelia were transferred to low-Pi MM (pH 8.0). Library 10. pH 8.0-enriched transcripts (60-min exposure)

Tester: mycelia from the $\mathrm{H} 6$ strain were transferred to low-Pi MM (pH 8.0), and incubated for $1 \mathrm{~h}$ at $28^{\circ} \mathrm{C}$. Driver: mycelia transferred to low-Pi MM (pH 5.0).

\section{CDNA sequencing and validation of differentially expressed genes}

The cDNAs corresponding to differentially expressed sequences in the SSH libraries were amplified by PCR, and the products were screened by reverse Northern hybridization, as described earlier [56]. The plasmids from arrayed clones that visually exhibited positive differential expression were sequenced using the M13 forward or reverse primers and BigDye Terminator Cycle Sequencing Kit in an automated ABI Prism ${ }^{\circ} 377$ DNA Sequencer (Applied Biosystems).

For validating differential gene expression by northern blot analysis, T. rubrum was cultivated as described for constructing the subtractive suppressive cDNA libraries. Samples containing approximately $15 \mu \mathrm{g}$ of total RNA were extracted with the Illustra RNAspin Isolation kit (GE Healthcare) and separated by electrophoresis on a $1.5 \%$ agarose gel containing formaldehyde. They were blotted onto Hybond-N+ membranes and hybridized with cDNA probes labeled with $\left[\alpha-{ }^{32} \mathrm{P}\right] \mathrm{dCTP}$.

\section{EST processing pipeline and annotation}

EST processing included base calling, quality control by Phred, and trimming (which involves the removal of low-quality vector and adapter sequences) by Cross
Match $[57,58]$. The accepted sequences contained at least 80 nucleotides with a Phred quality value higher than 20. Assembly of ESTs into clusters of overlapping sequences (contigs) was carried out with the CAP3 program using default parameters [59]. Singletons represent sequences that have no overlap with other ESTs. Unigenes (the number of contigs plus the number of singletons) are nonredundant sequences obtained after CAP3 assembly. Redundancy was estimated as the total number of ESTs minus the number of unigenes divided by the total number of ESTs, and the resulting value was transformed into a percentage.

For EST annotation, the unigenes were compared to the EST database (dbEST) and the nonredundant protein database (nr-GenBank) at the National Center for Biotechnology Information (NCBI, Bethesda, MD; http://www.ncbi.nlm.nih.gov). T. rubrum dbEST consists of ESTs from this species deposited in the public database. High-throughput scripts for the BLAST algorithms BLASTx and BLASTn [60] were used to search the nrGenBank and T. rubrum dbEST, respectively, using the Blosum 62 matrix and default BLAST parameters. Similarity search against dbEST using the BLASTn algorithm, excluding the sequences previously deposited by our group, was regarded to be significant when the expected value (e-value) was less than $1 \mathrm{e}^{-20}$. For BLASTx searching, the top 5 scoring hits with e-values lower than $1 \mathrm{e}^{-3}$ were used to annotate each EST. Sequences that did not return alignments with the established e-value cut-offs were considered as nomatches. Our results were also compared to TrED database http://www.mgc.ac.cn/TrED. The functional classification of these unigenes was performed according to the Functional Catalogue created by the Munich Information Center for Protein Sequences (MIPS), gathered through a BLAST comparison of the query sequence (unigenes) against MIPS-annotated proteins from Saccharomyces cerevisiae, Neurospora crassa, Fusarium graminearum, and Ustilago maydis [61,62]. This retrieves the MIPS accession number from the best hit (considering a minimum e-value of $1 \mathrm{e}^{-3}$ ), which in turn retrieves the functional category from the MIPS FunCat table. All computer analyses were performed on Intel-based computers ( $\mathrm{P} 4$ and Xeon) using the Linux-based operating system Fedora 6 . The scripts and programs were developed using the PERL language, and the web pages were created using CGI, Javascript, and HTML.

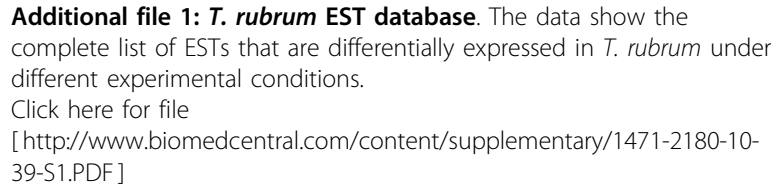


Additional file 2: $T$. rubrum unigenes database. The data show the complete list of unigenes that are differentially expressed in T. rubrum under each experimental condition, the novel T. rubrum genes

(highlighted) and their MIPS categorization.

Click here for file

[http://www.biomedcentral.com/content/supplementary/1471-2180-1039-S2.PDF ]

\section{Acknowledgements}

This study was supported by grants from the Brazilian funding agencies FAPESP, CNPq, CAPES, and FAEPA. We thank Dr AL Fachin for providing the F6 strain.

\section{Author details}

'Departamento de Genética, Faculdade de Medicina de Ribeirão Preto, Universidade de São Paulo, Ribeirão Preto 14049-900, SP, Brazil. ${ }^{2}$ Departamento de Bioquímica e Imunologia, Faculdade de Medicina de Ribeirão Preto, Universidade de São Paulo, Ribeirão Preto 14049-900, SP, Brazil. ${ }^{3}$ Current address: Faculdade de Ciências Farmacêuticas de Ribeirão Preto, Universidade de São Paulo, 14040-903, Ribeirão Preto, SP, Brazil.

\section{Authors' contributions}

NTAP participated in the construction of the CDNA gene library, clone isolation, data analysis, and drafted the manuscript. PRS performed the statistical and bioinformatics analyses. JPF participated in the construction of the CDNA gene library and clone isolation. FGP, HCSS, FCAM, DEG, FS, RAC, and JRCS constructed the SSH libraries, performed the northern blots, and collaborated on data analysis. RAF and MM were responsible for strain identification, designing of the culture and growth conditions, and cDNA sequencing. AR and NMMR designed the project, supervised the research study, and prepared the manuscript. All authors read and approved the final manuscript.

Received: 16 May 2009

Accepted: 8 February 2010 Published: 8 February 2010

\section{References}

1. Weitzman I, Summerbell RC: The Dermatophytes. Clin Microbiol Rev 1995, 8:240-259

2. Seebacher C, Bouchara JP, Mignon B: Updates on the epidemiology of dermatophyte infections. Mycopathologia 2008, 166:335-352.

3. Tsuboi R, Ko IJ, Takamori K, Ogawa H: Isolation of a keratinolytic proteinase from Trichophyton mentagrophytes with enzymatic activity at acidic pH. Infect Immun 1989, 57:3479-3483.

4. Blank IH: Measurement of $\mathrm{pH}$ of the skin surface. J Invest Dermatol 1939, 2:75-79.

5. Giddey K, Monod M, Barblan J, Potts A, Waridel P, Zaugg C, Quadroni M: Comprehensive analysis of proteins secreted by Trichophyton rubrum and Trichophyton violaceum under in vitro conditions. J Proteome Res 2007, 6:3081-3092.

6. Monod M: Secreted proteases from dermatophytes. Mycopathologia 2008, 166:285-294.

7. Brouta F, Descamps F, Fett T, Losson B, Gerday C, Mignon B: Purification and characterization of a $43.5 \mathrm{kDa}$ keratinolytic metalloprotease from Microsporum canis. Med Mycol 2001, 39:269-275.

8. Ferreira-Nozawa MS, Nozawa SR, Martinez-Rossi NM, Rossi A: The dermatophyte Trichophyton rubrum secretes an EDTA-sensitive alkaline phosphatase on high-phosphate medium. Braz J Microbiol 2003, 34:161-164.

9. Maranhão FCA, Paião FG, Martinez-Rossi NM: Isolation of transcripts overexpressed in human pathogen Trichophyton rubrum during growth in keratin. Microb Pathog 2007, 43:166-172.

10. Silveira HC, Gras DE, Cazzaniga RA, Sanches PR, Rossi A, Martinez-Rossi NM: Transcriptional profiling reveals genes in the human pathogen Trichophyton rubrum that are expressed in response to $\mathrm{pH}$ signaling. Microb Pathog 2010, 48:91-96.

11. Hwang L, Hocking-Murray D, Bahrami AK, Andersson M, Rine J, Sil A: Identifying phase-specific genes in the fungal pathogen Histoplasma capsulatum using a genomic shotgun microarray. Mol Biol Cell 2003, 14:2314-2326

12. Garaizar J, Brena S, Bikandi J, Rementeria A, Ponton J: Use of DNA microarray technology and gene expression profiles to investigate the pathogenesis, cell biology, antifungal susceptibility and diagnosis of Candida albicans. FEMS Yeast Res 2006, 6:987-998.

13. Costa M, Borges CL, Bailao AM, Meirelles GV, Mendonca YA, Dantas SF, de Faria FP, Felipe MS, Molinari-Madlum EE, Mendes-Giannini MJ, Fiuza RB, Martins WS, Pereira M, Soares CM: Transcriptome profiling of Paracoccidioides brasiliensis yeast-phase cells recovered from infected mice brings new insights into fungal response upon host interaction. Microbiology 2007, 153:4194-4207.

14. Liu T, Zhang Q, Wang L, Yu L, Leng W, Yang J, Chen L, Peng J, Ma L, Dong J, Xu X, Xue Y, Zhu Y, Zhang W, Yang L, Li W, Sun L, Wan Z, Ding G, Yu F, Tu K, Qian Z, Li R, Shen Y, Li Y, Jin Q: The use of global transcriptional analysis to reveal the biological and cellular events involved in distinct development phases of Trichophyton rubrum conidial germination. BMC Genomics 2007, 8:100.

15. Wang L, Ma L, Leng W, Liu T, Yu L, Yang J, Yang L, Zhang W, Zhang Q, Dong J, Xue Y, Zhu Y, Xu X, Wan Z, Ding G, Yu F, Tu K, Li Y, Li R, Shen Y, Jin Q: Analysis of the dermatophyte Trichophyton rubrum expressed sequence tags. BMC Genomics 2006, 7:255.

16. Yang J, Chen L, Wang L, Zhang W, Liu T, Jin Q: TrED: the Trichophyton rubrum Expression Database. BMC Genomics 2007, 8:250.

17. Martinez-Rossi NM, Peres NTA, Rossi A: Antifungal resistance mechanisms in dermatophytes. Mycopathologia 2008, 166:369-383.

18. Nagao $M$, Sugimura T: Molecular biology of the carcinogen, 4nitroquinoline 1-oxide. Adv Cancer Res 1976, 23:131-169.

19. Segato F, Nozawa SR, Rossi A, Martinez-Rossi NM: Over-expression of genes coding for proline oxidase, riboflavin kinase, cytochrome $c$ oxidase and an MFS transporter induced by acriflavin in Trichophyton rubrum. Med Mycol 2008, 46:135-139.

20. Paião FG, Segato F, Cursino-Santos JR, Peres NT, Martinez-Rossi NM: Analysis of Trichophyton rubrum gene expression in response to cytotoxic drugs. FEMS Microbiol Lett 2007, 271:180-186.

21. Yu L, Zhang W, Wang L, Yang J, Liu T, Peng J, Leng W, Chen L, Li R, Jin Q: Transcriptional profiles of the response to ketoconazole and amphotericin B in Trichophyton rubrum. Antimicrob Agents Chemother 2007, 51:144-153.

22. Zhang W, Yu L, Leng W, Wang $X$, Wang L, Deng $X$, Yang J, Liu T, Peng J, Wang J, Li S, Jin Q: CDNA microarray analysis of the expression profiles of Trichophyton rubrum in response to novel synthetic fatty acid synthase inhibitor PHS11A. Fungal Genet Biol 2007, 44:1252-1261.

23. Fachin AL, Ferreira-Nozawa MS, Maccheroni $W \mathrm{Jr}$, Martinez-Rossi NM: Role of the $A B C$ transporter TruMDR2 in terbinafine, 4-nitroquinoline $\mathrm{N}$-oxide and ethidium bromide susceptibility in Trichophyton rubrum. J Med Microbiol 2006, 55:1093-1099.

24. Graminha MAS, Rocha EMF, Prade RA, Martinez-Rossi NM: Terbinafine resistance mediated by salicylate 1-monooxygenase in Aspergillus nidulans. Antimicrob Agents Chemother 2004, 48:3530-3535.

25. Brasch J, Zaldua M: Enzyme patterns of dermatophytes. Mycoses 1994 37:11-16.

26. Apodaca G, McKerrow JH: Expression of proteolytic activity by cultures of Trichophyton rubrum. J Med Vet Mycol 1990, 28:159-171.

27. Ferreira-Nozawa MS, Silveira HCS, Ono CJ, Fachin AL, Rossi A, MartinezRossi NM: The $\mathrm{pH}$ signaling transcription factor PacC mediates the growth of Trichophyton rubrum on human nail in vitro. Med Mycol 2006, 44:641-645.

28. Hynes MJ: Induction of the acetamidase of Aspergillus nidulans by acetate metabolism. J Bacteriol 1977, 131:770-775.

29. Marzluf GA: Genetic regulation of nitrogen metabolism in the fungi. Microbiol Mol Biol Rev 1997, 61:17-32.

30. Todd RB, Andrianopoulos A, Davis MA, Hynes MJ: FacB, the Aspergillus nidulans activator of acetate utilization genes, binds dissimilar DNA sequences. EMBO J 1998, 17:2042-2054.

31. Thedei $\mathrm{Jr} \mathrm{G}$, Doubowetz TH, Rossi A: Effect of carbon source and extracellular $\mathrm{pH}$ on the acidification of the culture medium and phosphatase excretion in Neurospora crassa. Braz J Med Biol Res 1994, 27:1129-1134. 
32. Mirbod-Donovan F, Schaller R, Hung CY, Xue J, Reichard U, Cole GT: Urease produced by Coccidioides posadasii contributes to the virulence of this respiratory pathogen. Infect Immun 2006, 74:504-515.

33. Gaullier JM, Simonsen A, D'Arrigo A, Bremnes B, Stenmark H, Aasland R: FYVE fingers bind Ptdlns(3)P. Nature 1998, 394:432-433.

34. Schink KO, Bolker M: Coordination of cytokinesis and cell separation by endosomal targeting of a Cdc42-specific guanine nucleotide exchange factor in Ustilago maydis. Mol Biol Cell 2009, 20:1081-1088.

35. Stenmark H, Aasland R, Driscoll PC: The phosphatidylinositol 3-phosphatebinding FYVE finger. FEBS Lett 2002, 513:77-84.

36. Lee SA, Eyeson R, Cheever ML, Geng J, Verkhusha W, Burd C, Overduin M, Kutateladze TG: Targeting of the FYVE domain to endosomal membranes is regulated by a histidine switch. Proc Natl Acad Sci USA 2005, 102:13052-13057.

37. He J, Vora M, Haney RM, Filonov GS, Musselman CA, Burd CG, Kutateladze AG, Verkhusha W, Stahelin RV, Kutateladze TG: Membrane insertion of the FYVE domain is modulated by pH. Proteins 2009, 76(4):852-860.

38. Shimomura Y, Wada K, Fukuyama K, Takahashi Y: The asymmetric trimeric architecture of [2Fe-2S] IscU: implications for its scaffolding during ironsulfur cluster biosynthesis. J Mol Biol 2008, 383:133-143.

39. Bensen ES, Martin SJ, Li M, Berman J, Davis DA: Transcriptional profiling in Candida albicans reveals new adaptive responses to extracellular $\mathrm{pH}$ and functions for Rim101p. Mol Microbiol 2004, 54:1335-1351.

40. Maranhão FCA, Paiao FG, Fachin AL, Martinez-Rossi NM: Membrane transporter proteins are involved in Trichophyton rubrum pathogenesis. $J$ Med Microbiol 2009, 58:163-168.

41. Noguchi K, Fukazawa H, Murakami Y, Uehara Y: Nek11, a new member of the NIMA family of kinases, involved in DNA replication and genotoxic stress responses. J Biol Chem 2002, 277:39655-39665.

42. Galeote VA, Alexandre H, Bach B, Delobel P, Dequin S, Blondin B: Sfl1p acts as an activator of the HSP3O gene in Saccharomyces cerevisiae. Curr Genet 2007, 52:55-63.

43. Lorenz MC, Fink GR: The glyoxylate cycle is required for fungal virulence. Nature 2001, 412:83-86.

44. Lorenz MC, Fink GR: Life and death in a macrophage: role of the glyoxylate cycle in virulence. Eukaryot Cell 2002, 1:657-662.

45. Schnappinger D, Ehrt S, Voskuil MI, Liu Y, Mangan JA, Monahan IM, Dolganov G, Efron B, Butcher PD, Nathan C, Schoolnik GK: Transcriptional adaptation of Mycobacterium tuberculosis within macrophages: Insights into the phagosomal environment. J Exp Med 2003, 198:693-704.

46. Derengowski LS, Tavares AH, Silva S, Procopio LS, Felipe MS, Silva-Pereira I: Upregulation of glyoxylate cycle genes upon Paracoccidioides brasiliensis internalization by murine macrophages and in vitro nutritional stress condition. Med Mycol 2008, 46:125-134.

47. Ghannoum MA: Potential role of phospholipases in virulence and fungal pathogenesis. Clin Microbiol Rev 2000, 13:122-143.

48. Monod M, Capoccia S, Lechenne B, Zaugg C, Holdom M, Jousson O: Secreted proteases from pathogenic fungi. Int I Med Microbiol 2002, 292:405-419.

49. Jousson O, Lechenne B, Bontems O, Mignon B, Reichard U, Barblan J, Quadroni M, Monod M: Secreted subtilisin gene family in Trichophyton rubrum. Gene 2004, 339:79-88.

50. Zaugg C, Jousson O, Lechenne B, Staib P, Monod M: Trichophyton rubrum secreted and membrane-associated carboxypeptidases. Int J Med Microbiol 2008, 298:669-682.

51. Parisot $D$, Dufresne $M$, Veneault $C$, Lauge $R$, Langin T: clap1, a gene encoding a copper-transporting ATPase involved in the process of infection by the phytopathogenic fungus Colletotrichum lindemuthianum. Mol Genet Genomics 2002, 268:139-151.

52. Francis MS, Thomas CJ: Mutants in the CtpA copper transporting P-type ATPase reduce virulence of Listeria monocytogenes. Microb Pathog 1997, 22:67-78.

53. Zhu X, Gibbons J, Zhang S, Williamson PR: Copper-mediated reversal of defective laccase in a Deltavph1 avirulent mutant of Cryptococcus neoformans. Mol Microbiol 2003, 47:1007-1014.

54. Fachin AL, Maffei CML, Martinez-Rossi NM: In vitro susceptibility of Trichophyton rubrum isolates to griseofulvin and tioconazole. Induction and isolation of a resistant mutant to both antimycotic drugs. Mycopathologia 1996, 135:141-143.
55. Cove DJ: The induction and repression of nitrate reductase in the fungus Aspergillus nidulans. Biochim Biophys Acta 1966, 113:51-56.

56. Gras DE, Silveira HCS, Martinez-Rossi NM, Rossi A: Identification of genes displaying differential expression in the nuc-2 mutant strain of the mold Neurospora crassa grown under phosphate starvation. FEMS Microbiol Lett 2007, 269:196-200.

57. Ewing B, Hillier L, Wendl MC, Green P: Base-calling of automated sequencer traces using phred. I. Accuracy assessment. Genome Res 1998, 8:175-185.

58. Ewing B, Green P: Base-calling of automated sequencer traces using phred. II. Error probabilities. Genome Res 1998, 8:186-194.

59. Huang X, Madan A: CAP3: A DNA sequence assembly program. Genome Res 1999, 9:868-877.

60. Altschul SF, Madden TL, Schaffer AA, Zhang J, Zhang Z, Miller W, Lipman DJ: Gapped BLAST and PSI-BLAST: a new generation of protein database search programs. Nucleic Acids Res 1997, 25:3389-3402.

61. Mewes HW, Albermann K, Heumann K, Liebl S, Pfeiffer F: MIPS: a database for protein sequences, homology data and yeast genome information. Nucleic Acids Res 1997, 25:28-30.

62. Mewes HW, Frishman D, Guldener U, Mannhaupt G, Mayer K, Mokrejs M, Morgenstern B, Munsterkotter M, Rudd S, Weil B: MIPS: a database for genomes and protein sequences. Nucleic Acids Res 2002, 30:31-34.

63. Cox GM, McDade HC, Chen SC, Tucker SC, Gottfredsson M, Wright LC, Sorrell TC, Leidich SD, Casadevall A, Ghannoum MA, Perfect JR: Extracellular phospholipase activity is a virulence factor for Cryptococcus neoformans. Mol Microbiol 2001, 39:166-175.

64. Leidich SD, Ibrahim AS, Fu Y, Koul A, Jessup C, Vitullo J, Fonzi W, Mirbod F, Nakashima S, Nozawa Y, Ghannoum MA: Cloning and disruption of CaPLB1, a phospholipase B gene involved in the pathogenicity of Candida albicans. J Biol Chem 1998, 273:26078-26086.

65. Leng W, Liu T, Wang J, Li R, Jin Q: Expression dynamics of secreted protease genes in Trichophyton rubrum induced by key host's proteinaceous components. Med Mycol 2008, 1-7.

66. Brouta F, Descamps F, Monod M, Vermout S, Losson B, Mignon B: Secreted metalloprotease gene family of Microsporum canis. Infect Immun 2002, 70:5676-5683

67. Vermout S, Baldo A, Tabart J, Losson B, Mignon B: Secreted dipeptidyl peptidases as potential virulence factors for Microsporum canis. FEMS Immunol Med Microbiol 2008, 54:299-308.

68. Rees EM, Thiele DJ: From aging to virulence: forging connections through the study of copper homeostasis in eukaryotic microorganisms. Curr Opin Microbiol 2004, 7:175-184.

69. Munro CA, Bates S, Buurman ET, Hughes HB, Maccallum DM, Bertram G, Atrih A, Ferguson MA, Bain JM, Brand A, Hamilton S, Westwater C, Thomson LM, Brown AJ, Odds FC, Gow NA: Mnt1p and Mnt2p of Candida albicans are partially redundant alpha-1,2-mannosyltransferases that participate in O-linked mannosylation and are required for adhesion and virulence. J Biol Chem 2005, 280:1051-1060.

70. Wagener J, Echtenacher B, Rohde M, Kotz A, Krappmann S, Heesemann J, Ebel F: The putative alpha-1,2-mannosyltransferase AfMnt1 of the opportunistic fungal pathogen Aspergillus fumigatus is required for cell wall stability and full virulence. Eukaryot Cell 2008, 7:1661-1673.

71. Singh P, Ghosh S, Datta A: Attenuation of virulence and changes in morphology in Candida albicans by disruption of the $\mathrm{N}$ acetylglucosamine catabolic pathway. Infect Immun 2001, 69:7898-7903.

72. Barbosa MS, Bao SN, Andreotti PF, de Faria FP, Felipe MS, dos Santos Feitosa L, Mendes-Giannini MJ, Soares CM: Glyceraldehyde-3-phosphate dehydrogenase of Paracoccidioides brasiliensis is a cell surface protein involved in fungal adhesion to extracellular matrix proteins and interaction with cells. Infect Immun 2006, 74:382-389.

73. Kaufman G, Berdicevsky I, Woodfolk JA, Horwitz BA: Markers for hostinduced gene expression in Trichophyton dermatophytosis. Infect Immun 2005, 73:6584-6590.

doi:10.1186/1471-2180-10-39

Cite this article as: Peres et al.: Transcriptional profiling reveals the expression of novel genes in response to various stimuli in the human dermatophyte Trichophyton rubrum. BMC Microbiology 2010 10:39. 